protons and antiprotons, which weren't seen by PAMELA. A dark-matter particle from the dark sector - "even darker matter", quips Arkani-Hamed - would be seen only through a decay involving the forcecarrying dark photon, which would make positrons but not antiprotons.

Another motivation came from an intriguing result reported in 2004 by physicists at Brookhaven National Laboratory in Upton, New York. They found that the magnetic moment created by the spin and charge of the muon, a short-lived particle similar to an electron, did not match the predictions of the standard model. This anomaly, called the muon g-2, could also be rectified by a dark-sector force, says Arkani-Hamed. He adds that the idea is not as crazy as it sounds. "The whole setup is totally vanilla and conservative from a theorist's point of view," he says.

The predictions can be tested cheaply and relatively quickly. The main 6-gigaelectronvolt electron beam at Jefferson Lab has the right energy to probe the most likely mass range for a heavy photon. After the HPS's three-week test run, the beam will be shut down for an upgrade that will double its energy. This will allow the HPS and another project, the A Prime EXperiment (APEX), to explore other parts of the dark sector in 2015. A third proposal, called DarkLight, would use the beam that drives the lab's free-electron laser to look for heavy photons at lower energies (see 'Feeling in the dark').

Arkani-Hamed says that he won't be surprised if the future path of particle physics emerges from modest experiments such as those at the Jefferson Lab, rather than from work at CERN. "It could be that these much smaller, faster, cheaper, upstart, high-intensity, low-energy experiments might actually dig up evidence for new physics before the big monsters." -

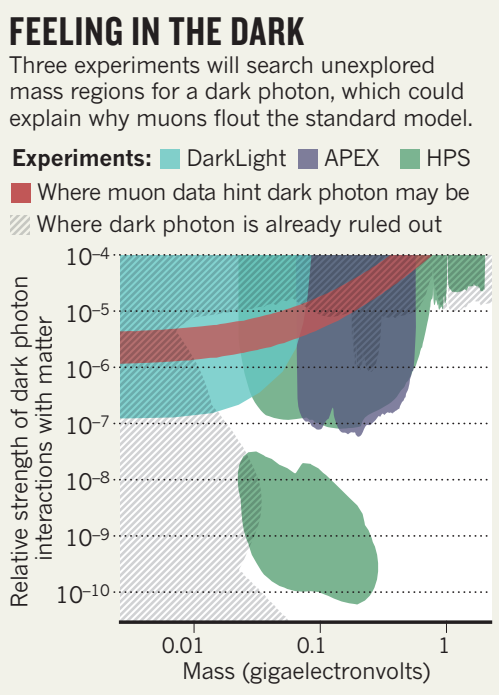

\title{
Cyprus Institute loses money and support
}

\section{Budget withheld as audit raises concerns.}

\section{BY ALISON ABBOTT}

$\mathrm{O}$ nce billed as the MIT of the Middle East, the Cyprus Institute in Nicosia is now so deep in crisis that it has not been able to pay last month's salaries. The Cypriot parliament is withholding the institute's 2012 budget amid a storm of criticism - from an audit exposing poor financial management to complaints about the management style of the institute's president, nuclear physicist Costas Papanicolas.

Last week, parliamentarians called for an independent analysis of the institute's activities to help to decide whether to continue financial support. The institute employs nearly 100 staff, but others have left for more secure environments. "If nothing constructive happens soon, the institute will collapse," says atmospheric chemist Jos Lelieveld of the Max Planck Institute for Chemistry in Mainz, Germany, who holds a joint position at the Cyprus Institute.

The multidisciplinary institute was conceived eight years ago by Hubert Curien, a former president of the CERN council, and John Joannides, then chief executive of the Cyprus Development Bank. Their aim was to create a high-quality research university that could bridge science communities in Europe and the Middle East, and build local research capacity. To sidestep public-sector bureaucracy, it was organized as a private, non-profit foundation.

The government provided seed money in 2005. The plan was for the institute to have six research centres and 2,500 graduate and undergraduate students by the end of 2009, and for it to be self-financing through fundraising, grants and student fees by 2010 .

Three research centres - in energy and environment, high-performance computing and archaeology - were launched in 2007. The institute formed ties with international institutions such as the Massachusetts Institute of Technology (MIT) in Cambridge and the University of Illinois at Urbana Champaign to help to plan research and offer training programmes. It also signed an agreement worth more than $€ 3$ million (US $\$ 4$ million) with MIT to design a solar-energy pilot plant able to generate electricity and desalinate seawater.

But in 2010, politicians, aware that the vicepresidents for research and for operations had resigned, began to question why the institute was still receiving public money. The institute had not expanded the number of research centres and the proposed student population had not emerged to provide the anticipated US\$62.5 million annual income. Moreover, no private donors had come forward.

"Naturally, we were concerned that an institute intended to be self-supporting was absorbing around $€ 8$ million of public money a year without the checks and balances that a public organization would have," says parliamentarian Nicholas Papadopoulos, one of the institute's most aggressive critics. Cyprus invests too little in research, he says, but "its small investments still need to be efficient".

In March 2011, parliament called in the auditor general. The audit report, delivered on 17 February this year, describes the business plan of the Cyprus Institute as unrealistic and over-ambitious, and criticizes a lack of transparency in its financial accounting, and in the hiring and paying of staff. It also notes that one-fifth of the staff left during 2011.

A number of scientists associated with the institute told Nature that they found Papanicolas' micro-management style intimidating.

"If nothing
constructive
happens soon,
the institute
will collapse."

They say it hindered their work and is holding the institute back, although most asked not to be identified. Andrea Pozzer, who left last year for a post at the International Centre for Theoretical Physics in Trieste, Italy, says "the interdisciplinary approach of the institute was exciting. But the general atmosphere was often unhappy and there were constant rumours about poor management that were not motivating".

Papanicolas denies that he interfered in dayto-day scientific activities.

"I agree it may not be easy to work with Costas Papanicolas if you don't gain his trust or live up to his high expectation," says theoretical physicist Edouard Brézin at the École Normale Supérieure in Paris, and chairman of the Cyprus Institute's board of trustees. But he adds that the institute should be more transparent.

The parliament's public-accounting committee endorsed the auditor's report last week and asked the finance committee to release the first quarter of the institute's 2012 budget. But Papadopoulos, who chairs the finance committee, is postponing discussions about this. 